\title{
Amorphous Co-Ni-P Alloys with High Saturation Magnetization Produced by Electrodeposition
}

\author{
Jamil Ahmad*, Katsuhiko Asami, Akira Takeuchi, Dmitri V. Louzguine and Akihisa Inoue \\ Institute of Materials Research (IMR), Tohoku University, Sendai 980-8577, Japan
}

The composition, structure and magnetic properties of high cobalt-containing Co-Ni-P alloys have been examined by controlling electrodepostion parameters. The alloys were deposited at $323 \mathrm{~K}$ from an electroplating solution consisting of nickel and cobalt chlorides and sodium hypophosphite. The current density and $\mathrm{pH}$ of the solution were controlled to determine the conditions of forming amorphous films. The alloys prepared at a current density of $150 \mathrm{~A} / \mathrm{m}^{2}$ and $\mathrm{pH}$ of 5.20 include both amorphous and crystalline phases. The increase of $\mathrm{pH}$ to above 5.20 results in the formation of amorphous alloys without crystalline phase. The conditions of $220 \mathrm{~A} / \mathrm{m}^{2}$ for current density and 5.24 for $\mathrm{pH}$ were optimum to prepare the amorphous alloy at the highest deposition rate of $5.19 \times 10^{-5} \mathrm{~kg} / \mathrm{m}^{2} / \mathrm{s}$. These amorphous alloys exhibited high saturation magnetization up to $1.3 \mathrm{~T}$ with coercivity of about $20 \mathrm{kA} / \mathrm{m}$.

(Received January 30, 2003; Accepted March 10, 2003)

Keywords: cobalt-based alloys, electrodepostion, amorphous phase, magnetic property

\section{Introduction}

Studies on metallic amorphous alloys and their functional properties have been an important subject for scientists and researchers during the last two decades. This has been attributed to novel mechanical, ${ }^{1-4)}$ magnetic $^{5-8)}$ and catalytic $^{9-11)}$ properties and excellent corrosion resistance ${ }^{12-17)}$ for these materials. Among magnetic amorphous materials, Cobased alloys are important and have been produced by various techniques including rapid quenching, ${ }^{18,19)}$ physical vapor deposition, ${ }^{20)}$ chemical or electroless plating ${ }^{21,22)}$ and electrodepostion. ${ }^{23-29)}$ The alloys produced by electrodepostion include $\mathrm{Co}-\mathrm{P}, \mathrm{Co}-\mathrm{W}$ and $\mathrm{Co}-\mathrm{Ni}-\mathrm{P}$ etc. It is known that these Co-based magnetic alloys have relatively low saturation magnetization values below 1.0 T. Recently, Myung et $a l{ }^{30)}$ have produced $\mathrm{Co}-\mathrm{Ni}-\mathrm{P}$ crystalline alloys having high cobalt and low phosphorus contents. It has been characterized that these alloys exhibit rather high saturation magnetization in the range of 1.2 to $1.4 \mathrm{~T}$. In this work, we examine optimum conditions for the formation of amorphous alloys with relatively high saturation magnetization values up to about $1.2 \mathrm{~T}$ from a similar electroplating solution.

\section{Experimental}

The composition of the electroplating bath is shown in Table 1. It consists of cobalt and nickel chlorides as a source of $\mathrm{Co}$ and $\mathrm{Ni}$ ions, respectively, and sodium hypophosphite as a source of phosphorus. Boric acid was added as a bath stabilizer. Sodium chloride was added to improve the conductivity of the solution, while sodium saccharin was added to improve the quality of the deposit. $\mathrm{pH}$ of the solution was controlled by sodium citrate. It also acts as a complexing agent for cobalt ions and maintains the cobalt contents of the alloys at higher percentages. $\mathrm{pH}$ remained constant during the deposition. Fresh solution was used for each deposition.

Copper plates of $3.25 \times 10^{-4} \mathrm{~m}^{2}$ in surface area were used

*Corresponding auther: mirza@imr.tohoku.ac.jp
Table 1 Composition and operating conditions for the electroplating bath.

\begin{tabular}{ll}
\hline Basic bath composition & \\
\hline $\mathrm{NiCl}_{2} \cdot 6 \mathrm{H}_{2} \mathrm{O}$ & $0.2 \mathrm{~mol} / \mathrm{L}$ \\
$\mathrm{CoCl}_{2} \cdot 6 \mathrm{H}_{2} \mathrm{O}$ & $0.15 \mathrm{~mol} / \mathrm{L}$ \\
$\mathrm{NaH}_{2} \mathrm{PO}_{2} \cdot \mathrm{H}_{2} \mathrm{O}$ & $0.3 \mathrm{~mol} / \mathrm{L}$ \\
$\mathrm{H}_{3} \mathrm{BO}_{3}$ & $0.4 \mathrm{~mol} / \mathrm{L}$ \\
$\mathrm{NaCl}$ & $0.7 \mathrm{~mol} / \mathrm{L}$ \\
$\mathrm{C}_{7} \mathrm{H}_{4} \mathrm{NNaO}_{3} \mathrm{~S}$ & $0.03 \mathrm{~mol} / \mathrm{L}$ \\
\hline Operating conditions & \\
\hline Temperature & $323 \mathrm{~K}$ \\
Time & $1.8 \mathrm{ks}$ \\
pH & $4.04-5.37$ \\
Current density & $50-220 \mathrm{~A} / \mathrm{m}^{2}$ \\
\hline
\end{tabular}

as substrates and cobalt plate as anode or counter electrode. Before electroplating, the copper plates were mechanically polished on $\mathrm{SiC}$ papers up to 2000 grit and washed in an alkaline solution. Then, they were chemically polished in an acidic solution, dried and used for electroplating. Potential on the substrate surface was measured against saturated calomel electrode (SCE). The constant current was applied by using a Hokuto Denko HZ-3000 electrochemical measuring system. The temperature of the bath was maintained at $323 \mathrm{~K}$ by a thermostat. The weight of the substrate was measured before $\left(W_{1}\right)$ and after $\left(W_{2}\right)$ the plating and the difference $(\Delta W)$ was taken as the weight of the deposited alloy, which was used for the calculation of magnetic induction values.

The crystalline and amorphous structures were determined by XRD. The thermal stability of the deposited alloys was determined by DSC using SII-320 DSC system. The amorphicity was also examined by transmission electron microscopy (TEM). The chemical composition was determined with a scanning electron microscope (SEM, Hitachi S800) equipped with Kevex energy dispersive spectroscopy (EDS) system. Magnetic hysteresis loops (applied field vs. magnetic induction) for the deposited alloys were measured with a vibrating sample magnetometer (VSM). Since the specimens for magnetic measurements consisted of $\mathrm{Co}-\mathrm{Ni}-\mathrm{P}$ 
alloy films deposited on copper substrate, their magnetic properties included the contribution from the copper substrate. This contribution was corrected by measuring the hysteresis loop for unplated copper substrate under similar conditions and subtracting the later value from the former one.

\section{Results}

Figure 1 shows the effect of current density on the composition of the alloys electroplated at a $\mathrm{pH}$ of 4.04. In this case, no sodium citrate was added to the bath. It is observed that the cobalt content of the alloy is about 14 at $\%$ at a current density of $50 \mathrm{~A} / \mathrm{m}^{2}$ and increases rapidly to 73 at $\%$ with an increase of current density to $90 \mathrm{~A} / \mathrm{m}^{2}$. At the same time, phosphorus content decreases from 5.2 to 2.0 at $\%$. However, the composition remains approximately constant in the range from 90 to $150 \mathrm{~A} / \mathrm{m}^{2}$. With further increasing current density to above $150 \mathrm{~A} / \mathrm{m}^{2}$, the cobalt content again decreases and the phosphorus content increases. The alloys deposited in the range of 90 to $150 \mathrm{~A} / \mathrm{m}^{2}$ are of interest because of high cobalt and low phosphorus contents. Such alloys are expected to exhibit better soft magnetic properties.

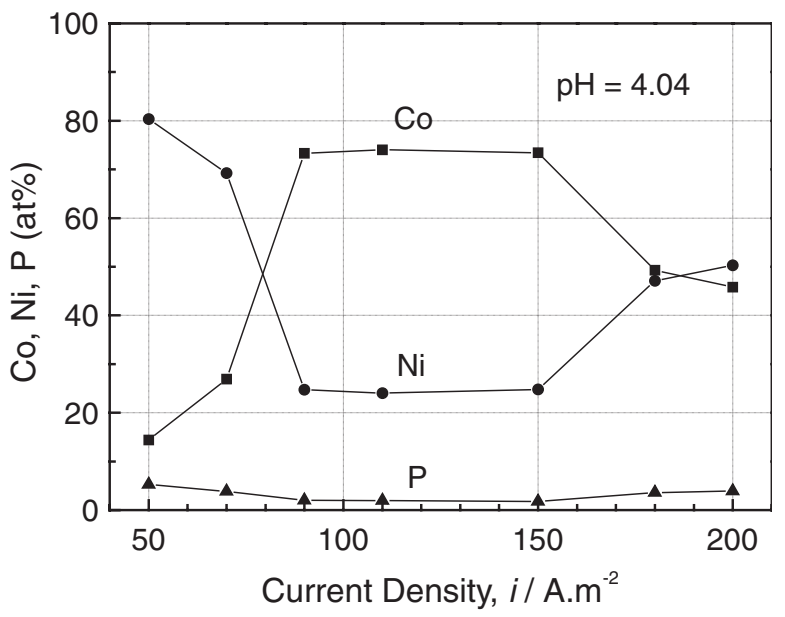

Fig. 1 Effect of current density on the composition of electrodeposited alloys at $\mathrm{pH}$ of 4.04 .

It is recognized that the structure becomes finer in this specific range of current density. Figure 2 shows SEM images of the surface of the alloys deposited in the specific range, together with that of the alloy deposited at $50 \mathrm{~A} / \mathrm{m}^{2}$.
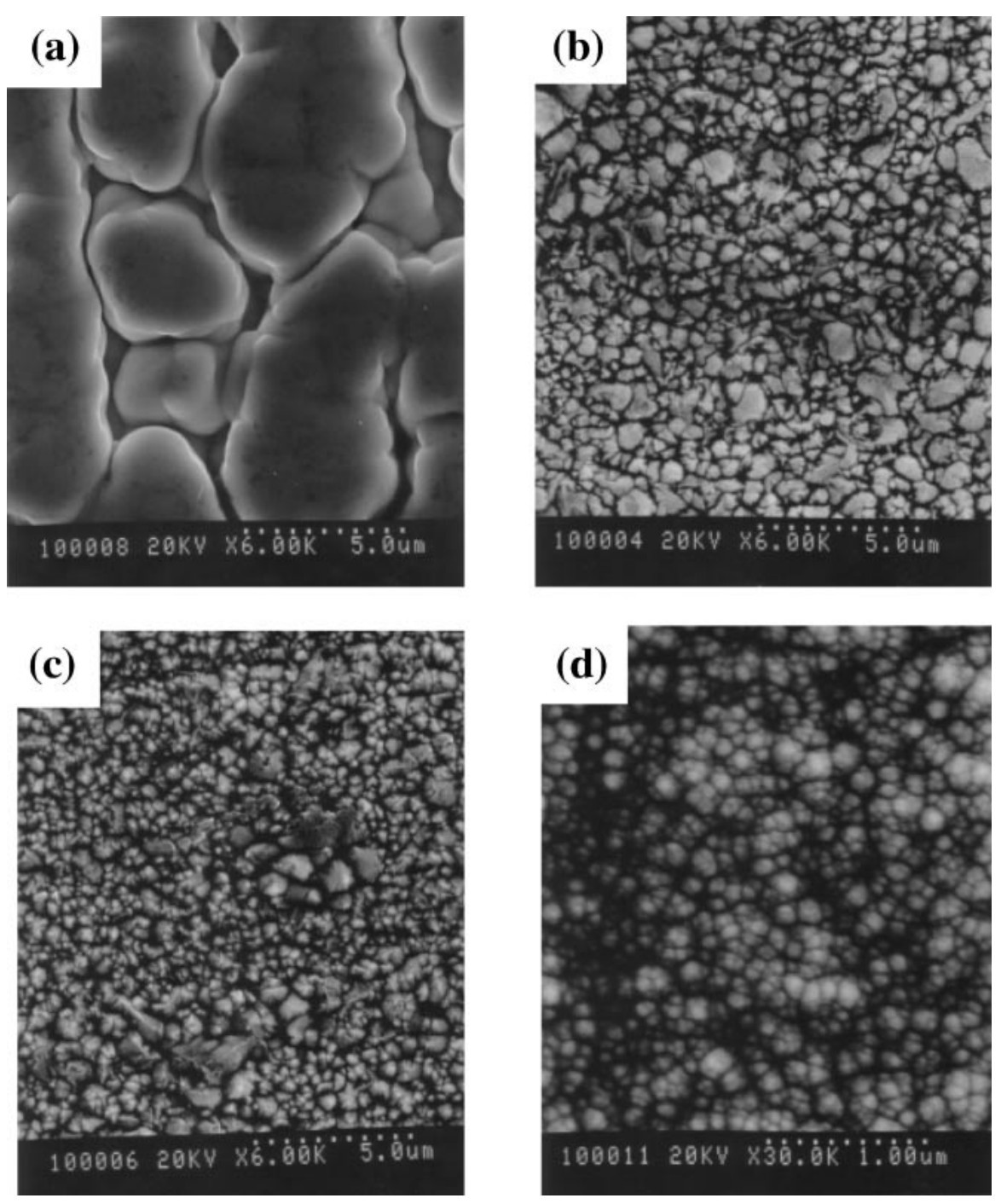

Fig. 2 Surface features of alloys deposited at pH of 4.04 and current density of (a) $50 \mathrm{~A} / \mathrm{m}^{2}$, (b) $90 \mathrm{~A} / \mathrm{m}^{2}$, (c) $110 \mathrm{~A} / \mathrm{m}^{2}$ and (d) $150 \mathrm{~A} / \mathrm{m}^{2}$. 
The micrograph (d) is shown at higher magnification because it has smoother surface structure invisible at lower magnification. It is clearly visible from these micrographs that the surface becomes finer with increasing current density. The surface ruggedness of the alloy deposited at $150 \mathrm{~A} / \mathrm{m}^{2}$ is of the order of $250 \mathrm{~nm}$.

Figure 3 shows X-ray diffraction patterns of the abovementioned alloys. The alloys prepared at current densities of 50 and $70 \mathrm{~A} / \mathrm{m}^{2}$ show nickel peaks, while those deposited from 90 to $150 \mathrm{~A} / \mathrm{m}^{2}$ show cobalt peaks. However, the cobalt alloys are highly textured along (002) plane of hexagonal phase. The alloys deposited at 50 and $70 \mathrm{~A} / \mathrm{m}^{2}$ also show nickel phosphide peaks, while those deposited at 90 to $150 \mathrm{~A} /$ $\mathrm{m}^{2}$ show cobalt phosphide peaks.

Since the finest structure for the high cobalt-containing alloys was obtained at $150 \mathrm{~A} / \mathrm{m}^{2}$, the effect of $\mathrm{pH}$ was studied at this current density. Figure 4 shows the effect of $\mathrm{pH}$ on the composition of the alloys deposited at a current density of $150 \mathrm{~A} / \mathrm{m}^{2}$. The $\mathrm{pH}$ was changed by the addition of sodium citrate in the solution. Sodium citrate also acts as a complexing agent for cobalt and thus in the electrodeposited alloys maintains high cobalt contents at higher $\mathrm{pH}$ values. It is evident from Fig. 4 that up to the $\mathrm{pH}$ of 5.15, the cobalt content of the deposited alloys is in the range of 74 to 78 at $\%$, while the phosphorus content increases from 1.76 at $\%$ at 4.04 $\mathrm{pH}$ to 4.3 at $\%$ at $5.15 \mathrm{pH}$. With an increase of phosphorus content, it is seen that the structure texture changes from (002) plane to (100) plane as shown in Fig. 5. When the pH of the plating solution increases to 5.20, the phosphorus
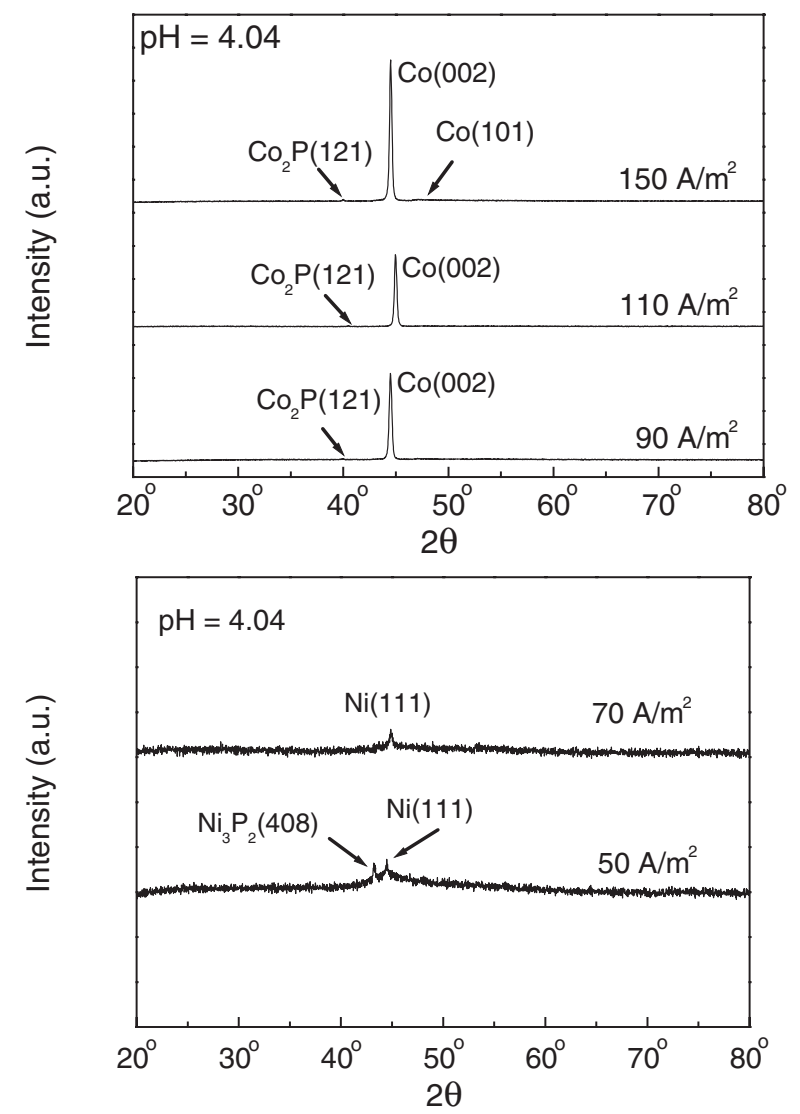

Fig. 3 X-ray diffraction patterns for alloys deposited at $\mathrm{pH}$ of 4.04 and different current densities.

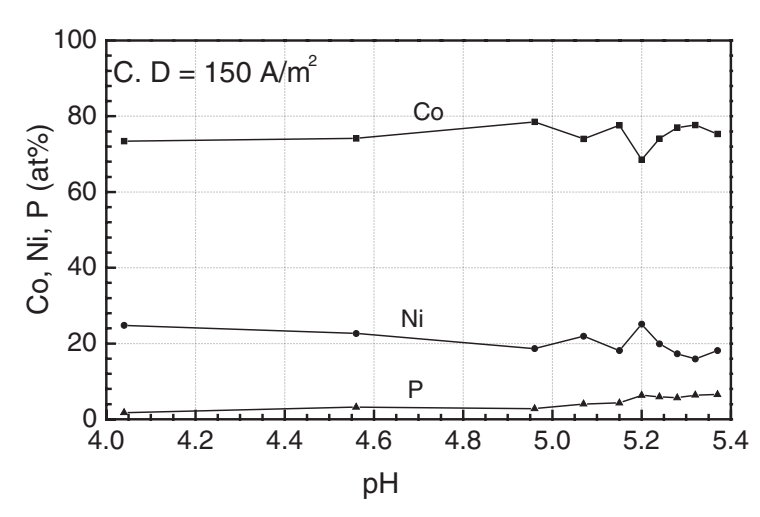

Fig. 4 Effect of $\mathrm{pH}$ on the composition of electrodeposited alloys at current density of $150 \mathrm{~A} / \mathrm{m}^{2}$.

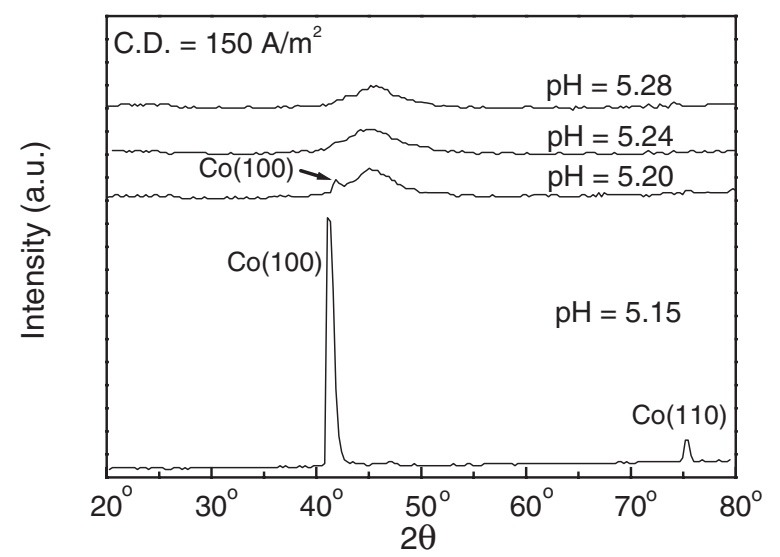

Fig. 5 X-ray diffraction patterns for alloys deposited at current density of $150 \mathrm{~A} / \mathrm{m}^{2}$ and different $\mathrm{pH}$ values.

content increases to 6.3 at $\%$ and an amorphous phase appears in the deposited alloy. In this case, the cobalt content also decreases to 68 at $\%$. With a further increase in $\mathrm{pH}$, the phosphorus content does not change and remains approximately constant (6at\%). However, the cobalt content increases and the structure becomes completely amorphous as far as determined by XRD.

Figure 6 shows the effect of $\mathrm{pH}$ on the deposition rate of the alloys. The deposition rate decreases with an increase in $\mathrm{pH}$. It is evident that the $\mathrm{pH}$ value for the formation of films

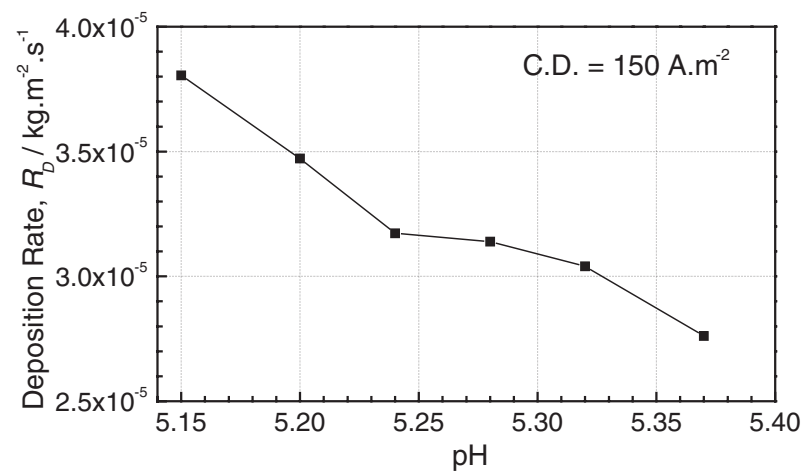

Fig. 6 Effect of $\mathrm{pH}$ on the deposition rate of alloys electrodeposited at current density of $150 \mathrm{~A} / \mathrm{m}^{2}$. 
with a completely amorphous structure at the highest deposition rate is 5.24. Therefore, the effect of current density was studied at a constant $\mathrm{pH}$ of 5.24.

Figure 7 shows the effect of current density on the composition of the deposited alloys at the $\mathrm{pH}$ of 5.24. It is seen that the composition is not affected much by current density and the cobalt content in the alloys is in the range of 74 to 78 at $\%$, while the phosphorus content lies in the range of 5 to 6 at $\%$. However, the quality of the films formed at current densities higher than $220 \mathrm{~A} / \mathrm{m}^{2}$ was not good and they contained entrapped salt. It is seen in Fig. 8 that the deposition rate increases with increasing current density. However, the use of current densities higher than $220 \mathrm{~A} / \mathrm{m}^{2}$ is not advisable because of salt entrapment.

Figure 9 shows the electron diffraction pattern of the alloy deposited at a current density of $220 \mathrm{~A} / \mathrm{m}^{2}$ and a $\mathrm{pH}$ of 5.24 . The diffraction pattern reveals typical halos due to the formation of an amorphous phase. Figure 10 shows the DSC curve of the same alloy. The curve shows two crystallization peaks. The onset point lies at $514 \mathrm{~K}$ for the first peak and at $683 \mathrm{~K}$ for the second peak. These results also show that this alloy has an amorphous structure.

Figure 11 shows the changes in the saturation magnetization $\left(I_{\mathrm{s}}\right)$ and remanence $\left(I_{\mathrm{r}}\right)$ with $\mathrm{pH}$ for the amorphous alloys deposited at a current density of $150 \mathrm{~A} / \mathrm{m}^{2}$. The saturation

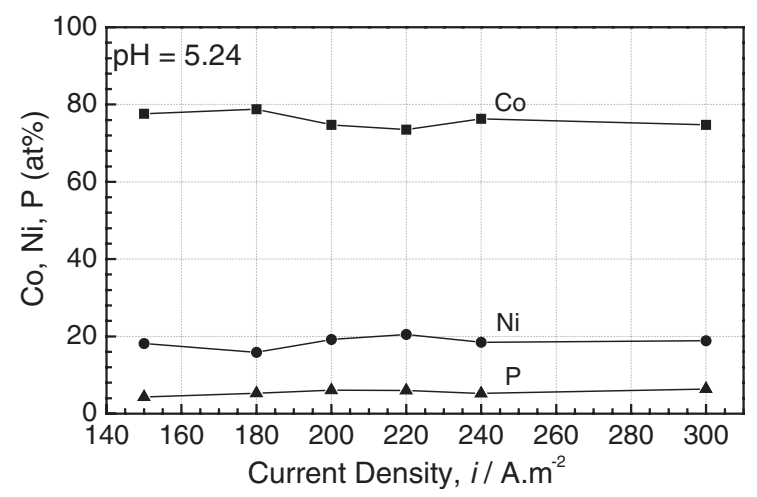

Fig. 7 Effect of current density on the composition of alloys electrodeposited at $\mathrm{pH}$ of 5.24 .

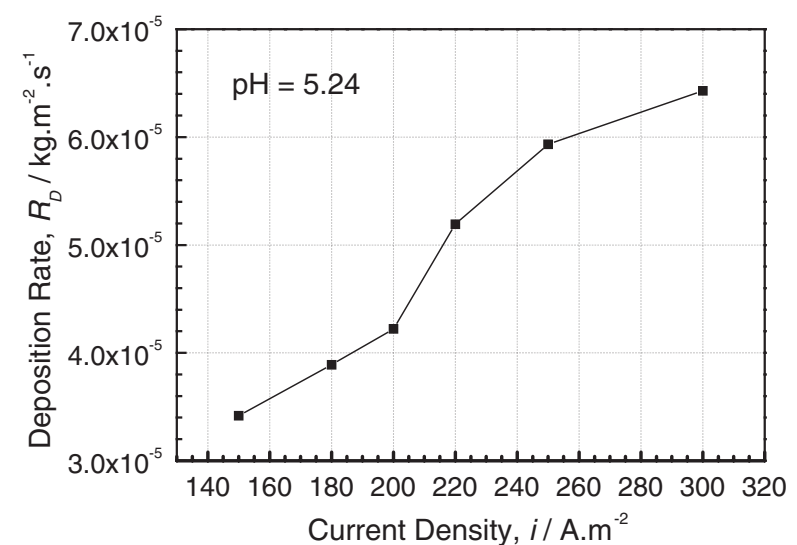

Fig. 8 Effect of current density on the deposition rate of alloys electrodeposited at a $\mathrm{pH}$ of 5.24.

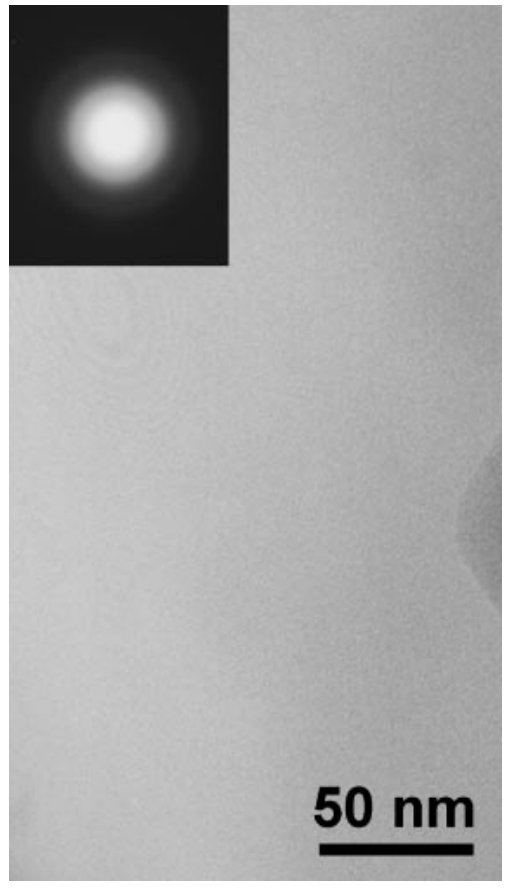

Fig. 9 TEM diffraction pattern of the alloy deposited at current density of $220 \mathrm{~A} / \mathrm{m}^{2}$ and $\mathrm{pH}$ of 5.24 .

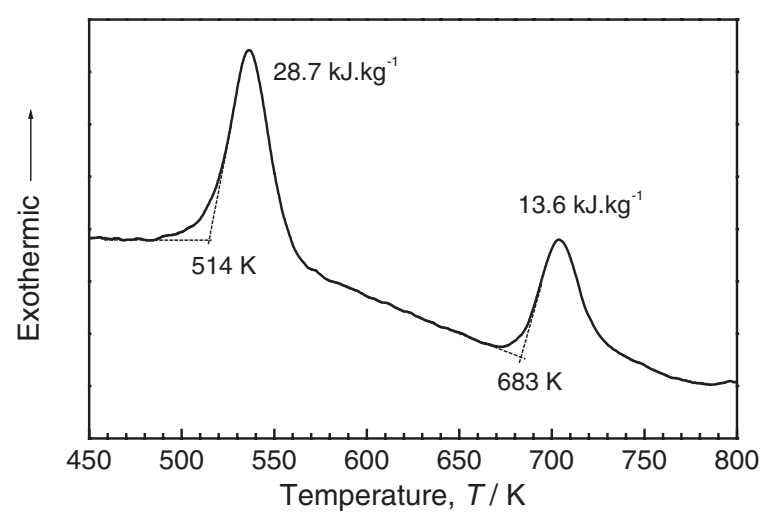

Fig. 10 DSC curve of the alloy deposited at current density of $220 \mathrm{~A} / \mathrm{m}^{2}$ and $\mathrm{pH}$ of 5.24 .

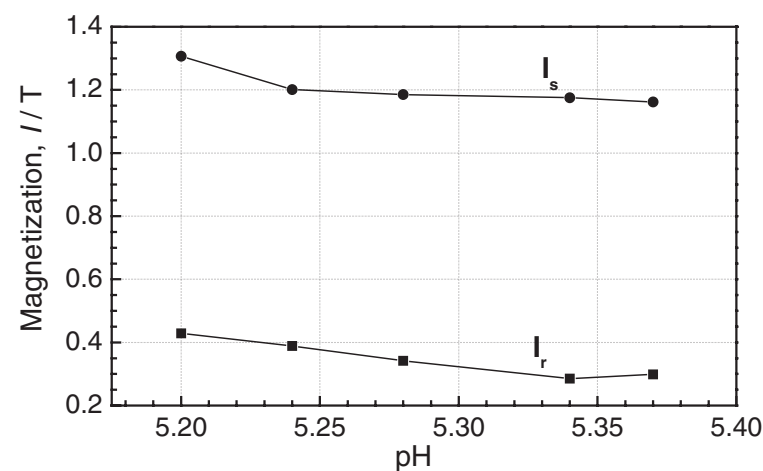

Fig. 11 Effect of $\mathrm{pH}$ on the saturation magnetization $\left(I_{\mathrm{s}}\right)$ and remanence $\left(I_{\mathrm{r}}\right)$ of alloys electrodeposited at current density of $150 \mathrm{~A} / \mathrm{m}^{2}$. 
magnetization is $1.30 \mathrm{~T}$ for the alloy containing crystalline phase deposited at $\mathrm{pH}$ of 5.20 and decreases from $1.20 \mathrm{~T}$ at $\mathrm{pH}=5.24$ to $1.16 \mathrm{~T}$ at $\mathrm{pH}=5.37$ for the alloys containing only an amorphous phase. The remanence also decreases with increasing $\mathrm{pH}$ of the solution.

The coercivities of these alloys are shown in Fig. 12. These alloys show larger coercivities and cannot be regarded as a soft magnetic material. The reason for the larger coercivities for these amorphous alloys is not clear at present.

Figure 13 shows the saturation magnetization and remanence values for the alloys deposited at $\mathrm{pH}$ of 5.24 and various current densities. It is seen that the increase of the current density also causes a decrease in saturation magnetization and remanence. With an increase in current density from 150 to $220 \mathrm{~A} / \mathrm{m}^{2}$, the saturation magnetization drops from 1.20 to $1.06 \mathrm{~T}$. The effect of current density on coercivity is also similar to that of $\mathrm{pH}$. The coercivity decreases with an increase in the current density. Figure 14 shows that an increase of current density from 150 to $220 \mathrm{~A} /$ $\mathrm{m}^{2}$ causes a decrease in coercivity from 21.2 to $18.3 \mathrm{kA} / \mathrm{m}$. The magnetic properties of the alloy deposited under the conditions of $220 \mathrm{~A} / \mathrm{m}^{2}$ and $5.24 \mathrm{pH}$ are also shown in Fig. 15. It is clearly evidenced from the hysteresis loop that this alloy has saturation magnetization of $1.06 \mathrm{~T}$, remanence of $0.26 \mathrm{~T}$ and coercivity of $18.3 \mathrm{kA} / \mathrm{m}$.

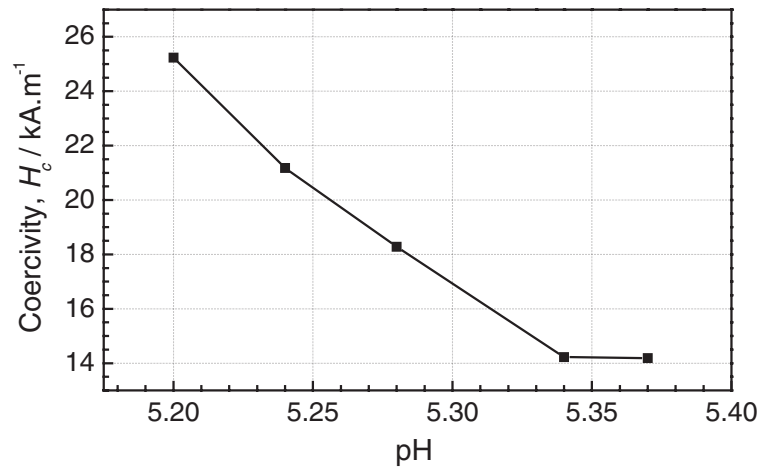

Fig. 12 Effect of $\mathrm{pH}$ on the coercivity of alloys electrodeposited at current density of $150 \mathrm{~A} / \mathrm{m}^{2}$.

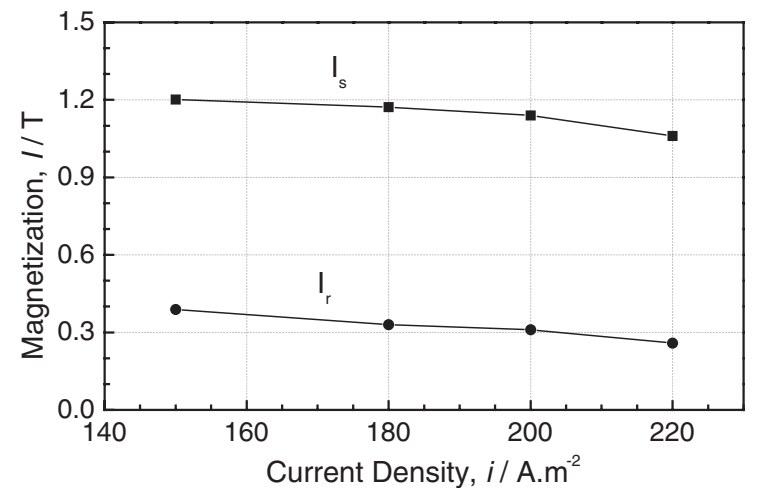

Fig. 13 Effect of current density on the saturation magnetization $\left(I_{\mathrm{S}}\right)$ and remanence $\left(I_{\mathrm{r}}\right)$ of alloys electrodeposited at $\mathrm{pH}$ of 5.24.

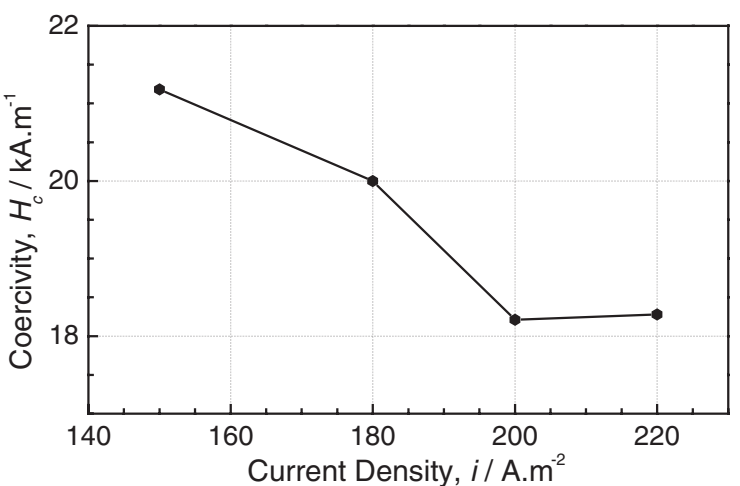

Fig. 14 Effect of current density on the coercivity of alloys electrodeposited at $\mathrm{pH}$ of 5.24 .

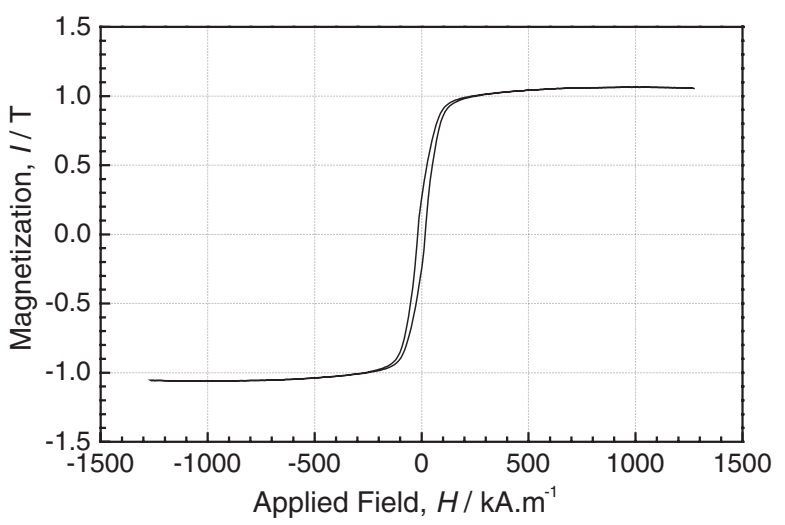

Fig. 15 Magnetic hysteresis loop for the alloy electrodeposited at current density of $220 \mathrm{~A} / \mathrm{m}^{2}$ and $\mathrm{pH}$ of 5.24 .

\section{Discussion}

\subsection{Current density and composition}

It is known that current density has a strong effect on the composition of electrodeposited $\mathrm{Co}-\mathrm{Ni}-\mathrm{P}$ alloys. However, the behavior of composition vs. current density curves shown in Figs. 1 and 7 is different. Although the behavior in Fig. 1, at low and high current densities, can be explained on the basis of thermodynamics and kinetics of the process, it is difficult to explain the behavior in the current density range of 90 to $150 \mathrm{~A} / \mathrm{m}^{2}$. Since the deposition potential for nickel is lower than that for cobalt, nickel is deposited preferentially at lower overpotentials associated with lower current densities. As the current density is increased, the cobalt concentration in the deposited alloys increases. Such a behavior is common for these alloys. On the other hand, the increase in the nickel content at the current densities higher than $150 \mathrm{~A} / \mathrm{m}^{2}$ is associated with the kinetics of the process. At such high current densities, the cobalt ions are consumed very fast. As a result, the cobalt ions are depleted in the vicinity of the electrode and this causes preferential deposition of nickel. When both ions are depleted in the vicinity of the electrode, the deposition is dependent only on the diffusion of ions from bulk solution to the electrode surface. Under such conditions, approximately equal amounts of the two elements should be deposited due to relatively comparable diffusion coefficients. 
It is evidenced from Fig. 1. However, the reason for the constant composition with increasing current density from 90 to $150 \mathrm{~A} / \mathrm{m}^{2}$ at $\mathrm{pH}$ of 4.04 remains unclear. Similarly, no prominent effect of current density is recognized on the composition of the alloys deposited at $\mathrm{pH}$ of 5.24. In this case sodium citrate seems to play an important role, acting as a complexing agent for cobalt ions, in controlling the kinetics of the deposition process. It must be noted that cobalt ions do not deplete from the solution overall, as cobalt is used for anode.

\subsection{Saturation magnetization and coercivity}

As shown in Figs. 11 to 15, the present $\mathrm{Co}-\mathrm{Ni}-\mathrm{P}$ amorphous alloys exhibit high saturation magnetization and coercivity than conventional amorphous $\mathrm{Co}-\mathrm{Ni}-\mathrm{P}$ alloys. The high saturation magnetization may be attributed to lower phosphorus contents of the alloys. The previously reported Co-Ni-P amorphous alloys have phosphorus contents more than about 10 at $\%$, while the present alloys have phosphorus content of 6 at $\%$ or less than $6 \%$. It is known ${ }^{29)}$ that Co-P binary amorphous alloys have higher coercivity when the phosphorus content is less than 9 at $\%$. The coercivity decreases drastically as the phosphorus content increases to above 9 at $\%$. There has been no detailed study on the reason for high coercivity of these $\mathrm{Co}-\mathrm{P}$ alloys. The $\mathrm{Co}-\mathrm{Ni}-\mathrm{P}$ alloys produced in the present work also exhibit high coercivity, but the reasons for the high saturation magnetization and coercivity for these alloy films remain unclear. To find out the influence of phosphorus content on the coercivity of these alloys, particularly, an optimum phosphorus content at which these amorphous alloys exhibit good soft magnetic properties is under investigation.

\section{Conclusions}

At $\mathrm{pH}$ of 4.04 , the composition of the $\mathrm{Co}-\mathrm{Ni}-\mathrm{P}$ alloys was found to be independent of current density in the current density range of 90 to $150 \mathrm{~A} / \mathrm{m}^{2}$. By controlling the $\mathrm{pH}$ in this range high $\mathrm{Co}-$ and low $\mathrm{P}$-containing amorphous alloys were prepared. The deposition rate of these amorphous alloys decreases with increasing $\mathrm{pH}$ of the bath, and increases with increasing current density. The alloy produced at a current density of $220 \mathrm{~A} / \mathrm{m}^{2}$ and a $\mathrm{pH}$ of 5.24 has the highest deposition rate. These amorphous alloys exhibited high saturation magnetizations of 1.06 to $1.2 \mathrm{~T}$ and relatively large coercivities of about $20 \mathrm{kA} / \mathrm{m}$.

\section{REFERENCES}

1) A. Inoue, W. Zhang, T. Zhang and K. Kurosaka: Acta Mater. 49 (2001) 2645-2652.

2) Y. Kawamura, K. Hayashi, J. Koike, A. Kato, A. Inoue and T. Masumoto: Mater. Sci. Forum 350 (2000) 111-116.

3) A. Inoue and H. Kimura: Mater. Sci. Eng. A-Struct. 286 (2000) 1-10.

4) A. Inoue, T. Zhang and Y. H. Kim: Mater. Trans., JIM 38 (1997) 749755.

5) A. Inoue, T. Zhang and A. Takeuchi: Appl. Phys. Lett. 71 (1997) 464466.

6) A. Inoue and B. L. Shen: Mater. Trans. 43 (2002) 2350-2353.

7) D. H. Shin, H. Niedoba, Y. Henry, F. Machizaud, V. Brien, D. Chumakov, R. Schafer and G. Suran: J. Magn. Magn. Mater. 249 (2002) 422-427.

8) J. Diaz, N. Hamdan, P. Jalil, Z. Hussain, S. M. Valvidares and J. M. Alameda: IEEE Trans. Magn. 38 (2002) 2811-2813 (Part 1).

9) Z. L. Ma, R. L. Jia, C. J. Liu and Z. T. Mi: Chem. Lett. 9 (2002) 884885 .

10) M. Janik-Czachor, A. Szummer, J. Bukowska, A. Molnar, P. Mack, S. M. Filipek, P. Kedzierzawski, A. Kudelski, M. Pisarek, M. Dolata and M. Varga: Appl. Catal. A-Gen. 235 (2002) 157-170.

11) Y. Lu, Z. T. Xiong, J. T. Li and J. Y. Lin: Catal. Lett. 78 (2002) 231237.

12) M. Mehmood, E. Akiyama, H. Habazaki, A. Kawashima, K. Asami and K. Hashimoto: Corros. Sci. 42 (2000) 361-382.

13) A. A. El-Moneim, E. Akiyama, H. Habazaki, A. Kawashima, K. Asami and K. Hashimoto: Mater. Sci. Eng. A-Struct. 267 (1999) 285-293.

14) M. Mehmood, B. P. Zhang, E. Akiyama, H. Habazaki, A. Kawashima, K. Asami and K. Hashimoto: Corros. Sci. 40 (1998) 1-17.

15) H. Habazaki, T. Sato, A. Kawashima, K. Asami and K. Hashimoto: Mater. Sci. Eng. A-Struct. 304 (2001) 696-700 (Sp. Iss. SI).

16) V. Cremaschi, I. Avram, T. Perez and H. Sirkin: Scr. Mater. 46 (2002) 95-100.

17) C. A. C. Souza, J. E. May, I. A. Carlos, M. F. de Oliveira, S. E. Kuri and C. S. Kiminami: J. Non-Cryst. Solids 304 (2002) 210-216.

18) A. Inoue and B. L. Shen: Mater. Trans. 43 (2002) 1230-1234 (Sp. Iss. SI).

19) W. Zhang, Y. Long, M. Imafuku and A. Inoue: Mater. Trans. 43 (2002) 1974-1978.

20) J. M. Fallon, C. A. Faunce and P. J. Grundy: J. Phys.-Condens. Mat. 12 (2000) 4075-4089.

21) S. Ya. Kiparisov and V. V. Vershinin: The Physics of Metals and Metallography 92 (2001) 25-30.

22) Yu. O. Akulova and N. O. Gonchukova: Glass Physics and Chemistry 24 (1998) 552-556.

23) J. M. Garcia, A. Asenjo, J. P. Sinnecker and M. Vazquez: J. Magn. Magn. Mater. 215 (2000) 352-354 (Sp. Iss. SI).

24) C. Favieres, M. C. Sanchez, E. Lopez, C. Aroca, P. Sanchez and V. Madurga: J. Magn. Magn. Mater. 177 (1998) 107-108 (Part 1).

25) G. Rivero, M. Multigner, J. M. Garcia, P. Crespo and A. Hernando: J. Magn. Magn. Mater. 177 (1998) 119-120 (Part 1).

26) A. Budniok and J. Kupka: Electrochim. Acta 34 (1989) 871-873.

27) A. Garcia-Arribas, M. L. Fdez-Gubieda and J. M. Barandiaran: Phys. Rev. B 61 (2000) 6238-6245.

28) M. M. V. Parente, O. R. Mattos, S. L. Diaz, P. L. Neto and F. J. F. Miranda: J. Appl. Electrochem. 31 (2001) 677-683.

29) A. Darkowski: Surf. Coat. Tech. 30 (1987) 131-135.

30) N. V. Myung, D. Y. Park, M. Schwartz, K. Nobe, H. Yang, C. K. Yang and J. W. Judy: 6th Int. Symp. on Magnetic Materials, Processes and Devices, Proc. Electrochem Soc. PV 2000-29 (2000). 